\title{
An Application of Polydopamine-dip Coating as a Gentle Surface Modification Process for Cryogel Disks
}

\author{
Gözde ÖZBEK ${ }^{1}$, Orhan GEZİCI ${ }^{1 *}$, Mevlüt BAYRAKCI ${ }^{2}$
}

\begin{abstract}
The process called "polydopamine-dip coating" was successfully applied to modify the surface of poly(2-hydroxyethyl methacrylate), PHEMA, cryogel disks for the first time. This facile surface modification process fitted very well to the chemistry of cryogels since the integrity of the cryogel disks was maintained during the whole process. Polydopamine (PDA) nanocoating process was observed to be homogeneously performed through the pores and there was a net color change from white to brown after $24 \mathrm{~h}$. The obtained (brownish) material (PHEMA-PDA) was characterized with respect to FTIR spectroscopy, $\mathrm{pH}_{\mathrm{pzc}}$, and water-holding capacity analyses. The potential of this new material was studied by utilizing it as an adsorbent for the adsorption of $\mathrm{Ni}$ (II) from synthetic aqueous solutions. The equilibrium adsorption data were analyzed on the basis of the Langmuir, the Freundlich, and the Temkin isotherm models. In general, Ni(II) adsorption on PHEMA-PDA was evaluated as a favorable process as depicted from the studied models. The proposed approach was found to be a promising postsurface modification process for tailoring the surface of monolithic cryogels without any difficult synthesis steps and harsh chemicals.
\end{abstract}

Keywords: Adsorption, cryogel, heavy metal, nanocoating, nickel, polydopamine.

${ }^{1}$ Gözde ÖZBEK (Orcid ID: 0000-0003-2835-5463), Orhan GEZİĊ (Orcid ID: 0000-0001-6808-2282), Niğde Ömer Halisdemir Üniversitesi, Fen-Edebiyat Fakültesi, Kimya Bölümü, Niğde, Türkiye

${ }^{2}$ Mevlüt BAYRAKCI (Orcid ID: 0000-0002-0416-2870), Karamanoğlu Mehmetbey Üniversitesi, Mühendislik Fakültesi, Biyomühendislik Bölümü, Karaman, Türkiye

*Sorumlu Yazar/Corresponding Author: Orhan GEZİCI, e-mail: ogezici@gmail.com

* Bu çalışma Gözde ÖZBEK'in Yüksek Lisans tezinden üretilmiştir. 


\section{INTRODUCTION}

Surface tailoring by appropriate modification processes and thus to obtain functional materials has become the core of today's popular disciplines. Depending on the chemistries of the solid support and the functional substance, very harsh conditions may be necessary, because most of the surface modification processes rely on a chemical attachment of a ligand onto the surface to be engineered. Chemical modification of the solid support under consideration is the method of choice over a physical modification because it yields materials with high chemical stability (Gezici and Bayrakci, 2015). However, the volume of chemicals needed and sometimes harsh experimental conditions required during the process led researchers finding alternative manners to perform desired modifications on a surface.

After its discovery in 2007 (Lee et al., 2007), the polydopamine (PDA) dip-coating process has been applied in surface modification of many materials (Jinhao et al., 2009; Lee et al., 2009; Waite, 2008) and today it has been recognized as a universal surface modification process (Yu et al., 2014). The simplicity of the process and hydrophilic nature of the PDA coating as well as its biocompatibility have increased the popularity of the process (Wang et al., 2015). The secret of the success of this process lies in the fact that dopamine hydrochloride can tightly adhere to almost all types of surfaces upon its auto polymerization process occurring on a surface under basic conditions (Lee et al., 2007). The presence of some functional groups (e.g. aromatic units, catechol, and amine) within the structure lends the PDA coating a multifunctional character associated with an extremely high hydrophilic nature (Wang et al., 2015; Yu et al., 2014).

Because of the above-mentioned aspects of PDA-coating, this surface modification process has been widely exploited in the preparation of functional materials for separation and purification methods. For example, it has been applied to prepare functional membranes (Fang et al., 2016; Li et al., 2009, 2012), magnetic nanoparticles (Wang et al., 2013), organic frameworks (Chen and Chen, 2017), carbon nanotubes (Yin et al., 2015), open tubular columns for capillary electrochromatography (Chen et al., 2012; Liang et al., 2014; Xiao et al., 2015; Zeng et al., 2010), capillaries for capillary electrophoresis (Zhang and Yang, 2019), aerogel sorbents (Tang et al., 2019; Zhan et al., 2019), composite of graphene hybridized PDA-kaolin (He et al., 2019), magnetic sub-micro spheres (Pan et al., 2019), ultrathin nanofiltration membranes (Wu et al., 2019), and etc. Some of the prepared materials are seen to have a potential (as adsorbent) in adsorption of some chemicals such as heavy metals (Mu et al., 2020; Wang et al., 2020), dyes (An et al., 2020; Chen et al., 2020), and bisphenol A (Sun et al., 2020).

Hence, it is seen in the literature that the PDA dip-coating process has been applied to the modification of various types of surfaces, while a study that critically focuses on the PDA-coated cryogels is seen to be lacking in the literature. Essentially, PDA dip-coating process is thought to be a nice manner for the modification of monolithic materials, like cryogels, without destroying their integrity. Cryogels are the hydrogels prepared at subzero temperatures, and these monolithic materials have been widely used in separation and purification processes. However, some difficulties encountered in surface modification of cryogels and the limited number of functional monomers constitute a real problem to prepare functional monolithic cryogels (Guven et al., 2018; Perçin et al., 2015). As mentioned above, the PDA dip-coating process can overcome some limitations when preparing functional monolithic cryogels, and that combining the chemistries of PDA and cryogels might be a critical contribution to prepare new types of functional monolithic adsorbents. Since heavy metals have undesired effects on health (Bişgin, 2019), in this preliminary study, we have focused on the adsorption behavior of $\mathrm{Ni}(\mathrm{II})$ on PDA-coated PHEMA cryogel disks. To the best of our knowledge, this is the first 
study that critically focuses on the surface functionalization of a monolithic cryogel (i.e. PHEMA) by means of the PDA dip-coating process.

\section{MATERIALS AND METHODS}

\section{Chemicals and apparatus}

2-hydroxyethyl methacrylate (HEMA; Aldrich, Germany), $N, N^{\prime}$-methylene-bis(acrylamide) (MBAAm; Fluka, USA), ammonium persulfate (APS; Sigma-Aldrich, Germany), $N, N, N^{\prime}, N^{\prime}-$ tetramethylethylenediamine (TEMED; Aldrich, Germany), dopamine hydrochloride (Sigma-Aldrich, Germany), and Tris (Sigma-Aldrich, Germany) buffer are the chemicals we used to prepare PDA-coated PHEMA disks (PHEMA-PDA). Ethyl alcohol (VWR, USA) is used to rinse the prepared disks after the synthesis of PHEMA-PDA. $\mathrm{Ni}\left(\mathrm{NO}_{3}\right)_{2} \cdot 6 \mathrm{H}_{2} \mathrm{O}$ (Alfa-Aesar, USA) was the probe substance we used throughout the adsorption experiments. Aqueous solutions of $\mathrm{Ni}$ (II) were prepared in pure water and the $\mathrm{pH}$ was adjusted to 6.0. $\mathrm{pH}$ adjustments were done by using dilute $\mathrm{HCl}$ (Merck, Germany) and $\mathrm{NaOH}$ (Sigma-Aldrich, Germany) solutions. $2 \mathrm{M} \mathrm{HNO}_{3}$ solution, which was prepared by diluting the stock $\mathrm{HNO}_{3}$ (Merck, Germany), was utilized as a stripping agent. All the chemicals were used as received, and ultrapure water was used throughout the study.

FTIR spectra of the dried materials were recorded on a Perkin-Elmer (USA) Spectrum-Two model ATR-FTIR spectroscopy instrument with a diamond crystal. A pH measurement system (VWR, USA) was utilized to measure $\mathrm{pH}$. The mixtures were shaken on a Heidolph (Germany) orbital shaker. An ultrasonic bath (Isolab (Germany)) was utilized to ultrasonicate the mixtures. Spectroscopic measurements were done by using a Shimadzu (Japan) AA 7000 flame atomic absorption spectrophotometer (FAAS). A Hitachi (Japan) SU5000 model instrument was used to take Scanning electron microscopy (SEM) images after coating the dry material with gold.

\section{Preparation of PHEMA disks}

PHEMA was synthesized according to a known procedure (Özkan et al., 2018) which is based on radical polymerization of the monomer HEMA and the cross-linker MBAAm. The monomer solution was prepared by using the distilled water which was degassed under vacuum to remove air oxygen. The mixture of monomers was prepared by combining two solutions comprised of (i) $0.60 \mathrm{~mL}$ HEMA in 2.0 $\mathrm{mL}$ water and (ii) $0.10 \mathrm{~g}$ MBAAm in $8.0 \mathrm{~mL}$ water. By the addition of APS $(0.020 \mathrm{~g})$ and TEMED (40 $\mu \mathrm{L}$ ) to this mixture, radical polymerization was initiated, and the final solution was quickly poured into $2.5 \mathrm{~mL}$ syringes previously housed in an ice-bath. Finally, the syringes were gently put into a freezer at $-20{ }^{\circ} \mathrm{C}$ for about $24 \mathrm{~h}$. By doing this, the cryogelation process was initiated. Afterward, the syringes were put out of the freezer for thawing at room temperature, and the obtained white PHEMA monoliths were washed three times with (i) distilled water and (ii) $30 \%(\mathrm{v} / \mathrm{v})$ ethyl alcohol solution $(50 \mathrm{~mL}$ in total for each). The rinsed PHEMA monoliths were carefully cut into disks having $8.8 \mathrm{~mm}$ i.d. and $0.5 \mathrm{~mm}$ thickness. In this way, the base material to be coated with PDA according to the following procedure have been prepared.

\section{Polydopamine dip-coating process: Preparation of PHEMA-PDA disks}

In the PDA dip-coating procedure, first, a dopamine hydrochloride solution was prepared by dissolving $0.200 \mathrm{~g}$ dopamine hydrochloride in $100 \mathrm{~mL}$ of a Tris buffer $(10 \mathrm{mM}$; $\mathrm{pH}=8.5)$. Wet PHEMAPDA disks were put into $100 \mathrm{~mL}$ of the buffer and agitated on an orbital shaker for about $24 \mathrm{~h}$ at room temperature. In the final step, the obtained brown PHEMA-PDA disks were washed with water and ethyl alcohol and ultrasonicated for about $3 \mathrm{~min}$ in each solvent. In order to check the success of the formation 
of PDA-coating throughout the disks, a PHEMA-PDA disk was cut into pieces and the progress of PDA formation was visually checked. The overall synthesis procedure is summarized in Fig. 1.

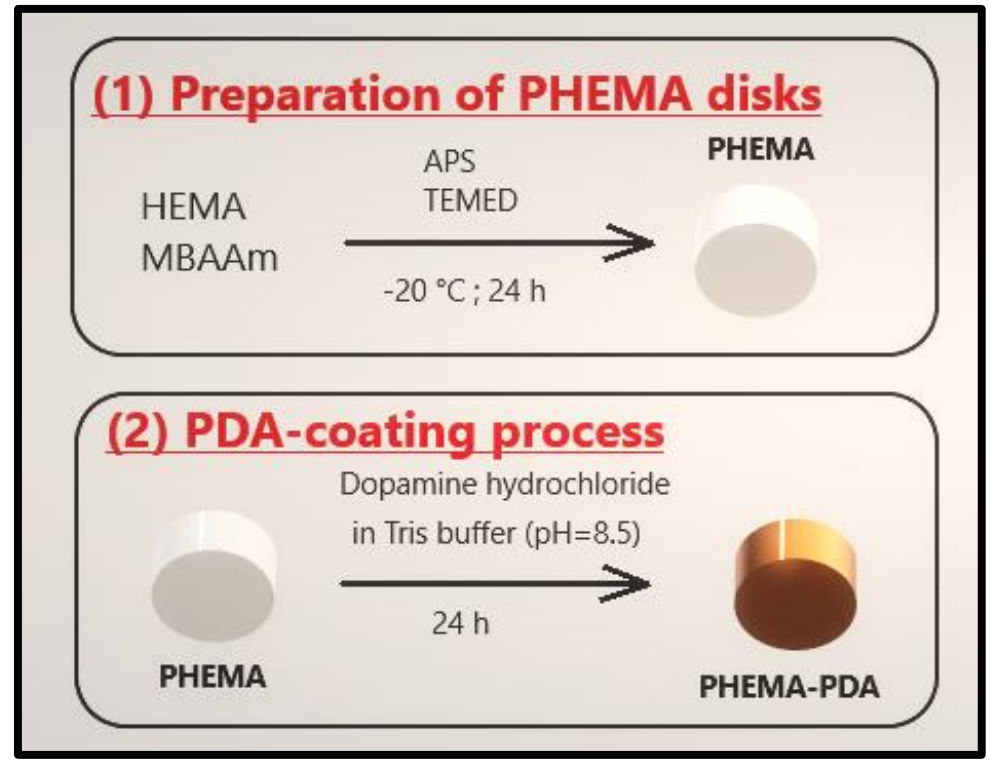

Fig. 1. A representative view for the procedure followed for the preparation of PHEMA-PDA disks

PHEMA-PDA was characterized by means of FTIR spectroscopy, $\mathrm{pH}_{\mathrm{pzc}}$ measurements, and waterholding capacity.

FTIR spectrum of PHEMA-PDA was directly recorded on the dried materials within the range $4000-650 \mathrm{~cm}^{-1}$ by ATR-FTIR spectroscopy. The recorded spectrum was compared with that of the support material, PHEMA.

The surface charge characteristics of the newly prepared material were studied using the mass titration method (Gezici et al., 2006; Noh and Schwarz, 1989; Reymond and Kolenda, 1999; Schwarz et al., 1984). For this purpose, 5 test tubes were taken and filled with $0.01 \mathrm{M} \mathrm{NaNO}_{3}$ solution. To each tube, $0,1,2,3$, and 6 piece(s) of PHEMA-PDA disk(s) were added. In this way, solid/suspension mass ratio was gradually increased to an extent that the medium $\mathrm{pH}$ reaches a steady state. When this steady state condition is achieved, the medium $\mathrm{pH}$ is governed by the solid material inside the tube, which is taken as the $\mathrm{pH}_{\mathrm{pzc}}$ of the studied material.

Microstructure of the prepared PHEMA-PDA disks was analyzed by SEM technique. Also, the water-holding capacity of PHEMA-PDA was determined from the difference between the wet and the dry weights of PHEMA-PDA disks.

\section{Adsorption experiments and isotherm modeling}

The classical batch adsorption experiments were applied to derive equilibrium adsorption data. For this purpose, $50.0 \mathrm{~mL}$ of analyte solutions having concentrations in the range $25-150 \mathrm{mg} \mathrm{L}^{-1}$, were shaken with one PHEMA-PDA disk (for each) over a predetermined time period ( $24 \mathrm{~h}$ ).

To determine amount of $\mathrm{Ni}$ (II) adsorbed, Ni(II)-bonded disks were put into $10 \mathrm{~mL} 2 \mathrm{M} \mathrm{HNO}_{3}$ solutions for $2 \mathrm{~h}$, and the acidic supernatant was subjected to FAAS analyses after diluting it adequately. In FAAS analyses, standard $\mathrm{Ni}$ (II) solutions were used to build an external calibration curve $\left(r^{2}=0.999\right)$ in the linear range.

The determined $C$ and $q$ values were then analyzed in terms of some common adsorption isotherm models (i.e. the Langmuir, the Freundlich, and the Temkin models) by using curve fitting techniques. 


\section{RESULTS AND DISCUSSIONS}

Before performing FTIR analyses and water-holding capacity measurements, the progress of PDAcoating process was checked by cutting a PHEMA-PDA disk into pieces. It was seen that PDA-coating process had been performed throughout the disks homogeneously without local distinctions. Hence, dopamine molecules are understood to be diffused properly through the pores of PHEMA, ensuring a desirable formation of PDA coating on the surface.

The prepared PHEMA-PDA disks were characterized by ATR-FTIR spectroscopy. Strong bands coming from the base material, PHEMA, constituted a serious problem to see the main bands of PDA coating clearly. Thus, the spectrum of PHEMA-PDA was observed to be one exhibiting a typical pattern observed for PHEMA cryogels with almost no distinguishing bands. Despite this limitation, fortunately, the bands related with $\mathrm{C}-\mathrm{N}$ stretching vibrations (for aromatic structures) and $\mathrm{C}-\mathrm{C}$ aromatic vibrations were observed around 1332 and $1609 \mathrm{~cm}^{-1}$, respectively, as weak shoulders (Fig. 2). The last is also attributed to indole or indoline structures existing in PDA (Dreyer et al., 2012). Since aromatic structures are not existing in PHEMA, these bands emerging after PDA-coating process make the two spectra somehow different and thus confirm the presence of PDA coating on the surface of PHEMA.

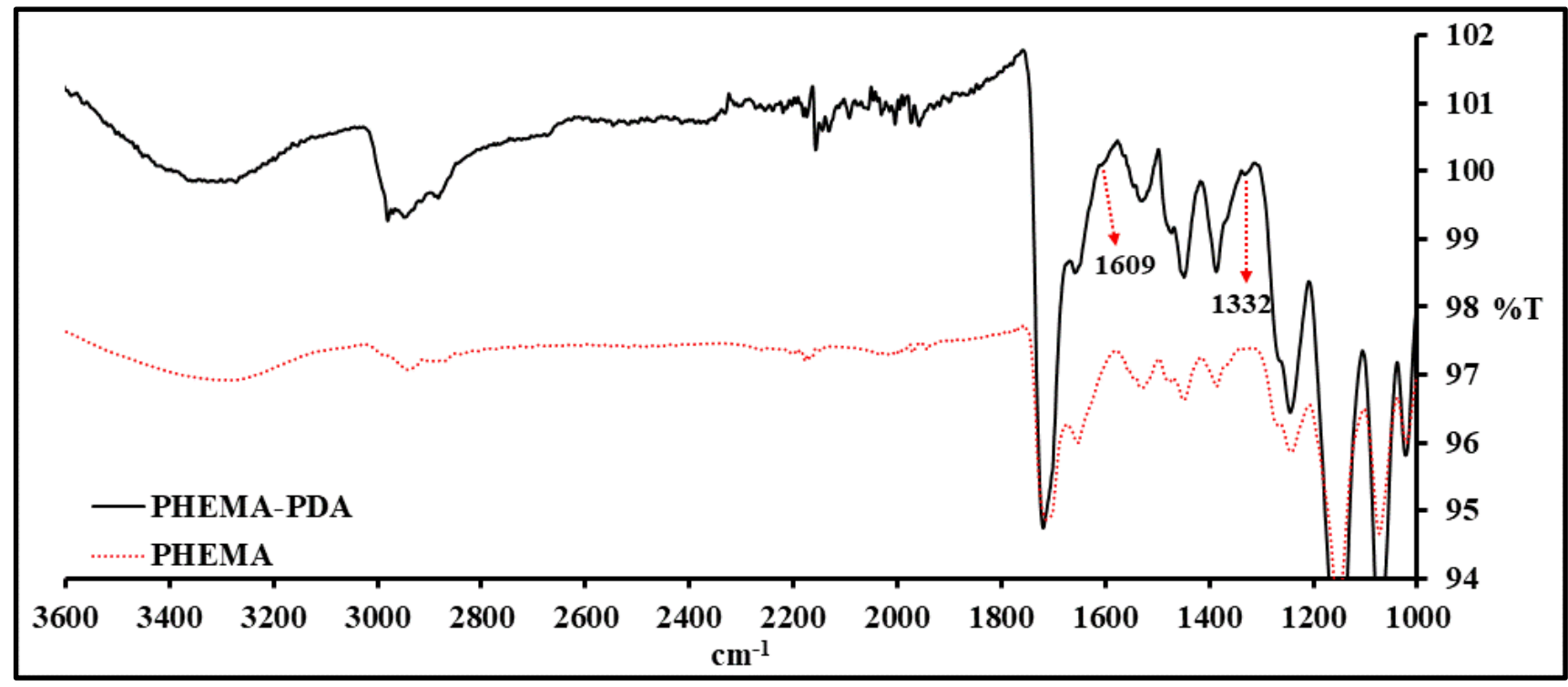

Fig. 2. FTIR spectra for PHEMA and PHEMA-PDA

$\mathrm{pH}_{\mathrm{pzc}}$ measurements confirmed the results of FTIR spectroscopy so that a clear decrement was observed in $\mathrm{pH}_{\mathrm{pzc}}$ after coating the surface of PHEMA with PDA. As it is seen in Fig. 3, the $\mathrm{pH}_{\mathrm{pzc}}$ value for PHEMA-PDA is around 4.5-5.0 which is less than the value we previously obtained for PHEMA $\left(\mathrm{pH}_{\mathrm{pzc}}=6.2\right)$ (Özkan et al., 2018). Hence, such an increment in surface acidity was evaluated as an indication for the surface coverage by a PDA layer. The calculated value is concordant to the previous reports on PDA-coated surfaces (Dong et al., 2016). Because of this moderately low $\mathrm{pH}_{\mathrm{pzc}}$ value, the surface of PHEMA-PDA becomes negatively charged at $\mathrm{pH}$ values higher than 5.0, because of this the material was evaluated as a convenient and an attractive option for the adsorption of cationic species. 


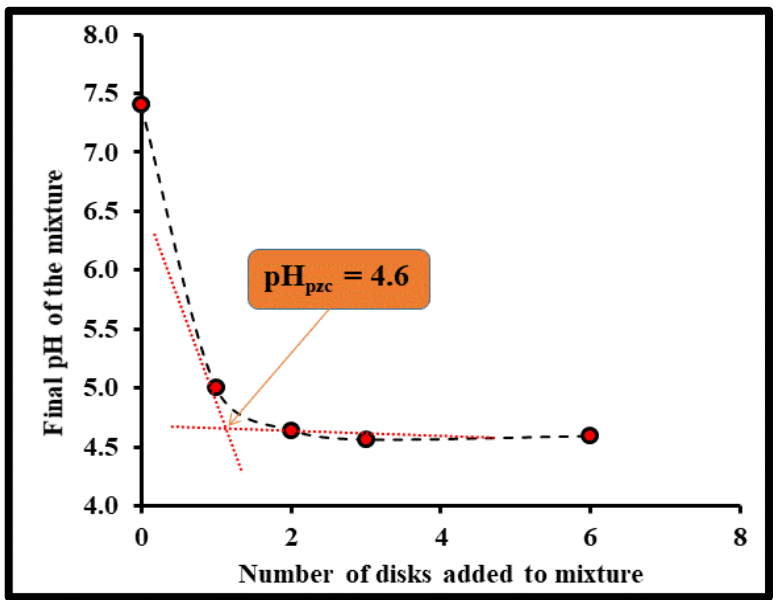

Fig. 3. Determination of $\mathrm{pH}_{\mathrm{pzc}}$ by the mass-titration method

Microporous structure of PHEMA-PDA was confirmed by SEM analyses (Fig. 4). As it is seen in the figure, PHEMA-PDA is made up of 10-20 $\mu \mathrm{m}$ size pores and this microstructure can be evaluated as a suitable medium for the solutions to diffuse through the pores easily.

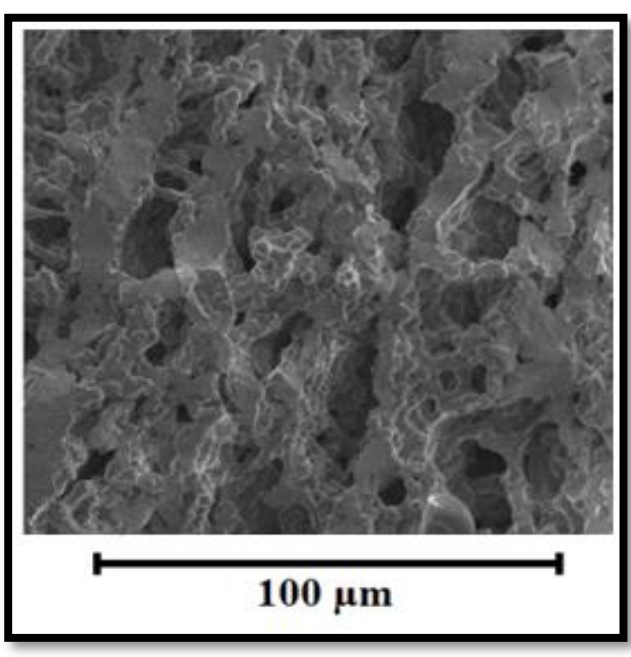

Fig. 4. SEM image for PHEMA-PDA

Water holding-capacity of PHEMA-PDA was determined in order to have some information about the role of PDA coating process on both morphology and hydrophilic character of PHEMA. Results showed that more than $80 \%$ of PHEMA-PDA structure was fully occupied by water molecules. This is a very typical behavior observed for cryogels (Özkan et al., 2018; Perçin et al., 2015) and confirms macroporous morphology and hydrophilic nature of PHEMA-PDA. Thus, PDA-coating process was found not to have a negative impact on the porous structure of the studied cryogel matrix.

\section{Adsorption isotherm modeling}

Adsorption is an interface phenomenon which is based on the mass-transfer from a fluid phase (i.e. liquid, gas) to a solid phase (Gezici and Ayar, 2009). The overall efficiency of the process is determined by the physicochemical properties of the solid phase (i.e. adsorbent) and the chemical species (i.e. adsorbate) adsorbed from the fluid phase. This is a complex phenomenon that different interaction types can take role during the mass-transfer. On the other hand, some mathematical equations called "adsorption isotherms" make it easy to have some information about the nature of the adsorption process under consideration. Today, many different adsorption isotherm models are existing in the literature 
(Foo and Hameed, 2010). Some of them (like the Langmuir and the Freundlich models) are the most widely used ones because of their adaptability to the adsorption from both gas and liquid phases.

The Langmuir model

The Langmuir (Langmuir, 1916) model considers a finite number of binding zones which have the same energy on the adsorbent. The chemical species under consideration are thought to be adsorbed onto these binding groups in such a way that a monolayer coverage is formed on the adsorbent surface eventually. Both the existence of a finite number of binding sites, and a monolayer coverage on the surface necessitate the presence of a "maximum saturation capacity $\left(q_{m}\right)$ " for particular adsorption process. The classical model equation for this non-linear isotherm model is given below (Foo and Hameed, 2010):

$q=\frac{q_{m} K_{b} C}{1+K_{b} C}$

where $C$ and $q$ stand for the equilibrium concentration of the analyte in fluid and solid phases, respectively. The Langmuir model constant $q_{m}$ represents the monolayer saturation capacity, while $K_{b}$ is known as the Langmuir binding constant. The last is also known as the affinity constant and it is related to the capability of an adsorbent to attract the analyte from dilute solutions. This isotherm model is very important in adsorption and chromatography (Guiochon et al., 1994) because the model is thermodynamically consistent, and has good adaptability to different processes.

Nonlinear least square curve fitting was applied to fit the classical Langmuir equation to the equilibrium adsorption data of Ni(II) on PHEMA-PDA (Fig. 5), and the fitted model parameters were given in Table 1. As it is seen in the figure, the Langmuir model did not represent the experimental data of $\mathrm{Ni}(\mathrm{II})$ adequately, according to the regression coefficient $\left(r^{2}=0.917\right)$. This behavior was probably because of the complex structure of PDA coating that such a multifunctional surface can interact with metal ions through different mechanisms. This argument was supported by the Scatchard plot analysis (Gezici et al., 2007; Scatchard, 1949) so that the data set was observed to be distributed on two different linear segments having negative slopes (Fig. 6). Each segment is attributed to different binding types having different affinities and capacities. Since both the segments are linear (at each respective concentration range) with a negative slope, for that segmented ranges, the Langmuir model adequately represents the data (but not for the whole studied concentration range).

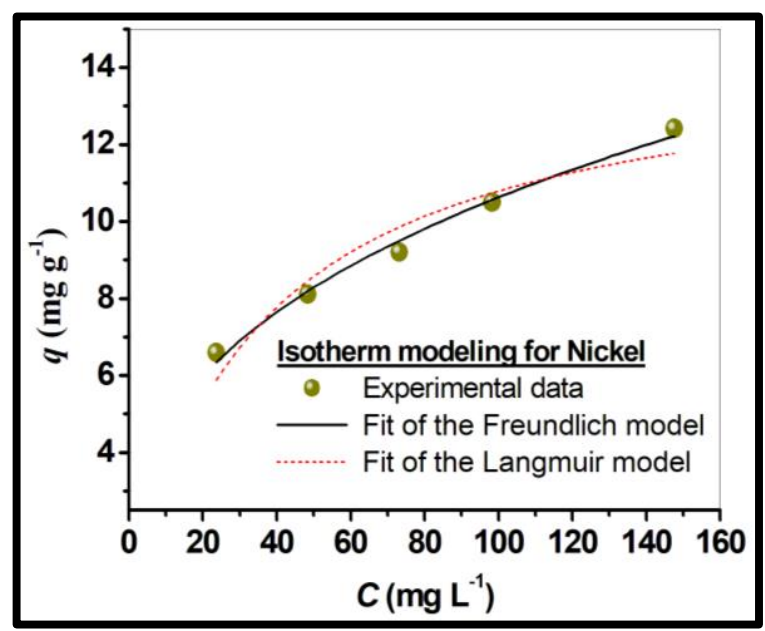

Fig. 5. The fit of the Langmuir and Freundlich models to the equilibrium adsorption data of Ni(II) 


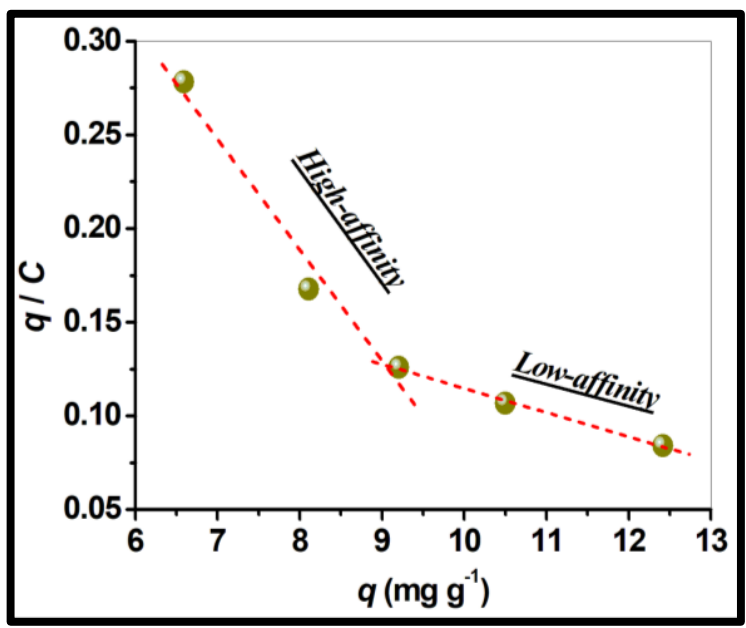

The Freundlich model

Fig. 6. The Scatchard plot for $\mathrm{Ni}(\mathrm{II})$

Another nonlinear isotherm model is the Freundlich model (Freundlich, 1906). This empirical model, usually, exhibits good fit to the experimental data. The model distinguishes from the Langmuir model with respect to the theoretical saturation capacity so that in the Freundlich model there is no isotherm model parameter related to the maximum theoretical capacity. On the contrary to the Langmuir model, the Freundlich model considers binding sites having different energies on the adsorbent. Hence, one of the most important aspects of this model is reflected by the model parameter called "heterogeneity index, $1 / n$ ". When the heterogeneity index lies in the range of $0<1 / n<1$, the related adsorption process is accepted as a beneficial one for the studied experimental conditions (Ahmaruzzaman and Sharma, 2005; Ayar et al., 2008). The classical model equation is written as follows:

$q=K_{F} C^{1 / n}$

where $K_{F}$ is the isotherm model parameter that combines both affinity and capacity terms.

The Freundlich model exhibited a better fit compared to the Langmuir model (Fig. 5). As it was inferred from the Scatchard plot analysis, the presence of more than one type of binding sites indicates a nonhomogeneous energy distribution on the surface for the whole concentration range of Ni(II). This is, probably, the main reason why the Freundlich model, which accounts for non-uniform distribution of adsorption energy and affinity over the heterogeneous surfaces (Foo and Hameed, 2010), best represents the experimental data. The fitted model parameter, $1 / n=0.36$, implies a beneficial process since it lies within the range $0 \leq 1 / n \leq 1$.

The Temkin model

Despite some limitations of the Temkin model in liquid-solid interfaces (Foo and Hameed, 2010), it is, widely used to explain the adsorption from aqueous solutions. The model accounts for indirect adsorbate-adsorbent interactions as well as adsorbate-adsorbate repulsions and supplies some information about the way of adsorption (i.e. physical, chemical). The Temkin isotherm model (Tempkin and Pyzhev, 1940) characterizes the adsorption process by a uniform distribution of binding energies up to some maximum values (Araújo et al., 2018; Pourfaraj et al., 2017). The isotherm model equation is given below:

$q=\frac{R T}{b_{T}} \ln A_{T}+\frac{R T}{b_{T}} \ln C$ 
where $b_{T}$ is the Temkin constant representing the heat of adsorption $\left(\mathrm{J} \mathrm{mol}^{-1}\right), A_{T}$ is the Temkin isotherm constant $\left(\mathrm{L} \mathrm{g}^{-1}\right), R$ is the gas constant $\left(8.314 \mathrm{~J} \mathrm{~mol}^{-1} \mathrm{~K}^{-1}\right)$, and $T$ is the absolute temperature $(\mathrm{K})$.

The Temkin model did not exhibit a good fit to the equilibrium adsorption data of $\mathrm{Ni}$ (II) (Fig. 7). Therefore, the repulsions between the adsorbates were thought not to be occurring in high degrees.

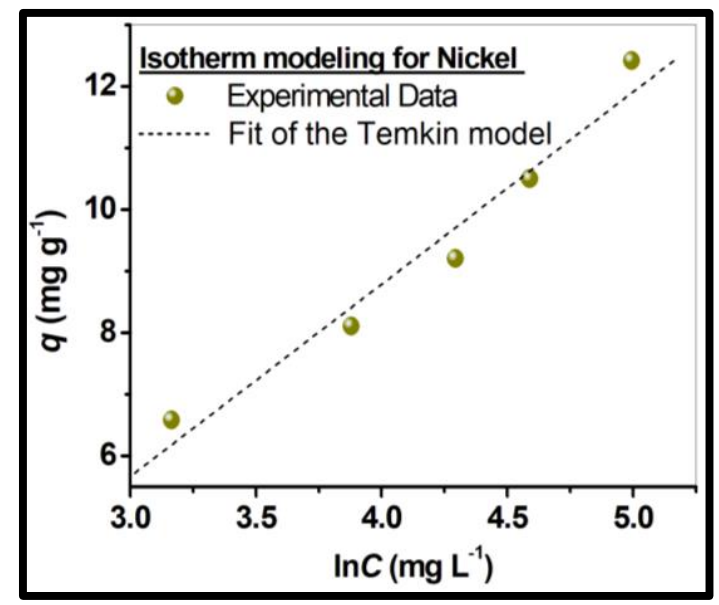

Fig. 7. The fit of the Temkin model to the equilibrium adsorption data of $\mathrm{Ni(II)}$

As a conclusion, valuable information about the adsorption of Ni(II) onto PHEMA-PDA was gathered from the applied isotherm models. The nature of Ni(II) adsorption onto the studied monolithic adsorbent was thought to be a process which is mainly governed by more than one types of binding sites having different energies. Furthermore, adsorbate-adsorbate repulsions were concluded not to be important in the adsorption of $\mathrm{Ni}$ (II). Finally, the way of adsorption on PHEMA-PDA disks were understood to be different for $\mathrm{Ni}$ (II) and crystal violet (Beyazova and Gezici, 2018) as inferred form the adsorption isotherm models: The adsorption of crystal violet on PHEMA-PDA was found to be adequately represented by the Langmuir model, while the Freundlich model was found to be better in modeling the adsorption data of $\mathrm{Ni}(\mathrm{II})$.

Table 1. The fitted model parameters, and the goodness of model fits

\begin{tabular}{ccccccccc}
\hline & Langmuir & \multicolumn{3}{c}{ Freundlich } & \multicolumn{3}{c}{ Temkin } \\
\hline $\begin{array}{c}q_{m} \\
\left(\mathrm{mg} \mathrm{g}^{-1}\right)\end{array}$ & $\begin{array}{c}K_{b} \\
\left(\mathrm{~L} \mathrm{mg}^{-1}\right)\end{array}$ & $r^{2}$ & $1 / n$ & $K_{F}$ & $r^{2}$ & $\begin{array}{c}A_{T} \\
\left(\mathrm{~L} \mathrm{~g}^{-1}\right)\end{array}$ & $\begin{array}{c}b_{T} \\
\left(\mathrm{~kJ} \mathrm{~mol}^{-1}\right)\end{array}$ & $r^{2}$ \\
\hline n.a. $^{\text {a }}$ & n.a. $^{\text {a }}$ & 0.9241 & $0.36 \pm 0.02$ & $2.04 \pm 0.20$ & 0.9901 & n.a. $^{\text {a }}$ & n.a. $^{\text {a }}$ & 0.9601 \\
\hline
\end{tabular}

a In the present study, the model fits having the regression coefficients less than 0.98 were evaluated as poor model fits and thus the fitted model parameters were, intentionally, not reported as they make no sense.

\section{CONCLUSIONS}

PDA dip-coating process was successfully applied to functionalize PHEMA disks. The equilibrium adsorption data of $\mathrm{Ni}$ (II) were modeled on the basis of the Langmuir, the Freundlich, and the Temkin models.

The new material exhibited its "heterogeneous face" in $\mathrm{Ni}(\mathrm{II})$ adsorption so that the adsorption data were only represented by the Freundlich model. The other two studied isotherm models were found not to be applicable for the examined concentration range. On the other side, more than one types of binding sites having different affinities (and thus energies) might take role in $\mathrm{Ni}$ (II) adsorption on PHEMA-PDA as inferred from the Scatchard transformation of the Langmuir model. Since the Temkin model showed a poor fit to the data, the adsorbate-adsorbate repulsions were thought not be at a 
significant level for $\mathrm{Ni}(\mathrm{II})$, and thus the energy of adsorption was concluded not being one decreased linearly with the progress of adsorption.

As a conclusion, the adsorption behavior of Ni(II) on PHEMA-PDA was studied for the first time. As a generic character, Ni(II) adsorption on PHEMA-PDA was found to be a beneficial one as depicted from the Freundlich model. The ease of operation when performing the adsorption process with the disk form and little amount of chemicals used to prepare the disks make the proposed approach preferable in many adsorption processes. Thus, the PDA dip-coating process is suggested as a straightforward and an "elegant" process for the post-functionalization of monolithic materials like cryogels. Monolithic cryogels obtained by this process are promising materials in the adsorption of proteins, heavy metal ions, dyes, and etc. Hence, further studies are necessary to have a better understanding of the nature of adsorption on PDA-coated cryogels better.

\section{ACKNOWLEDGMENT}

Authors wish to thank Nigde Ömer Halisdemir University, and Karamanoglu Mehmetbey University for the facilities provided.

\section{REFERENCES}

Ahmaruzzaman M, Sharma DK, 2005. Adsorption of phenols from wastewater. Journal of Colloid and Interface Science. 287(1): 14-24.

An Y, Zheng H, Yu Z, Sun Y, Wang Y, et al., 2020. Functioned hollow glass microsphere as a self-floating adsorbent: Rapid and high-efficient removal of anionic dye. Journal of Hazardous Materials. 381: 120971.

Araújo CST, Almeida ILS, Rezende HC, Marcionilio SMLO, Léon JJL, de Matos TN, 2018. Elucidation of mechanism involved in adsorption of $\mathrm{Pb}$ (II) onto lobeira fruit ( Solanum lycocarpum ) using Langmuir, Freundlich and Temkin isotherms. Microchemical Journal. 137: 348-54.

Ayar A, Gürsal S, Gürten AA, Gezici O, 2008. On the removal of some phenolic compounds from aqueous solutions by using a sporopollenin-based ligand-exchange fixed bed - Isotherm analysis. Desalination. 219(1-3): 160-70.

Beyazova G, Gezici O, 2018. Dye Adsorption on Polydopamine-coated Monolithic Cryogel Disks. International Marmara Science and Social Sciences Congress, pp. 518-21

Bişgin AT, 2019. Surfactant-Assisted Emulsification and Surfactant-Based Dispersive Liquid-Liquid Microextraction Method for Determination of $\mathrm{Cu}(\mathrm{II})$ in Food and Water Samples by Flame Atomic Absorption Spectrometry. Journal of AOAC International. 102(5): 1516-22.

Chen B, Cao Y, Zhao H, Long F, Feng X, et al., 2020. A novel Fe3+-stabilized magnetic polydopamine composite for enhanced selective adsorption and separation of Methylene blue from complex wastewater. Journal of Hazardous Materials. 392: 122263.

Chen L, Zeng R, Xiang L, Luo Z, Wang Y, 2012. Polydopamine-graft-PEG antifouling coating for quantitative analysis of food proteins by CE. Analytical Methods. 4(9): 2852-59.

Chen Y, Chen Z, 2017. COF-1-modified magnetic nanoparticles for highly selective and efficient solid-phase microextraction of paclitaxel. Talanta. 165: 188-93.

Dong Z, Gong H, Gao M, Zhu W, Sun X, et al., 2016. Polydopamine Nanoparticles as a Versatile Molecular Loading Platform to Enable Imaging-guided Cancer Combination Therapy. Theranostics. 6(7): 1031-42.

Dreyer DR, Miller DJ, Freeman BD, Paul DR, Bielawski CW, 2012. Elucidating the structure of poly(dopamine). Langmuir. 28(15): 6428-35.

Fang M, Zhang H, Chen J, Wang T, Liu J, et al., 2016. A facile approach to construct hierarchical dense membranes via polydopamine for enhanced popylene/nitrogen separation. Journal of Membrane Science. 499: 290-300.

Foo KY, Hameed BH, 2010. Insights into the modeling of adsorption isotherm systems. Chemical Engineering Journal. 156(1): 2-10. 
Freundlich HMF, 1906. Über die Adsorption in Lösungen. Zeitschrift für Physikalische Chemie. 57: 385-470.

Gezici O, Ayar A, 2009. Stepwise frontal analysis to derive equilibrium sorption data for copper and aniline on functionalized sporopollenin. Clean - Soil, Air, Water. 37(4-5): 349-54.

Gezici O, Bayrakci M, 2015. Calixarene-engineered surfaces and separation science. Journal of Inclusion Phenomena and Macrocyclic Chemistry. 83(1-2): 1-18.

Gezici O, Kara H, Ayar A, Topkafa M, 2007. Sorption behavior of $\mathrm{Cu}(\mathrm{II})$ ions on insolubilized humic acid under acidic conditions: An application of Scatchard plot analysis in evaluating the $\mathrm{pH}$ dependence of specific and nonspecific bindings. Separation and Purification Technology. 55(1): 132-39.

Gezici O, Küçükosmanoğlu M, Ayar A, 2006. The adsorption behavior of crystal violet in functionalized sporopollenin-mediated column arrangements. Journal of Colloid and Interface Science. 304(2): 307-16.

Guiochon G, Shirazi SG, Katti AM, 1994. Fundamentals of Preparative and Nonlinear Chromatography. Boston, MA: Academic Press.

Guven I, Gezici O, Bayrakci M, Morbidelli M, 2018. Calixarene-immobilized monolithic cryogels for preparative protein chromatography. Journal of Chromatography A. 1558: 59-68.

He K, Zeng G, Chen A, Huang Z, Peng M, et al., 2019. Graphene hybridized polydopamine-kaolin composite as effective adsorbent for methylene blue removal. Composites Part B: Engineering. 161: 141-49.

Jinhao GAO, Hongwei GU, Bing XU, 2009. Multifunctional magnetic nanoparticles: design, synthesis, and biomedical applications. Accounts of Chemical Research. 42(8): 1097-1107.

Langmuir I, 1916. The constitution and fundamental properties of solids and liquids. Journal of the American Chemical Society. 38: 2221-95.

Lee H, Dellatore SM, Miller WM, Messersmith PB, 2007. Mussel-Inspired Surface Chemistry for Multifunctional Coatings. Science. 318(5849): 426-30.

Lee H, Rho J, Messersmith PB, 2009. Facile conjugation of biomolecu les onto surfaces via mussel adhesive protein inspired coatings. Advanced Materials. 21(4): 431-34.

Li B, Liu W, Jiang Z, Dong X, Wang B, Zhong Y, 2009. Ultrathin and stable active layer of dense composite membrane enabled by poly(dopamine). Langmuir. 25(13): 7368-74.

Li XL, Zhu LP, Jiang JH, Yi Z, Zhu BK, Xu YY, 2012. Hydrophilic nanofiltration membranes with selfpolymerized and strongly-adhered polydopamine as separating layer. Chinese Journal of Polymer Science (English Edition). 30(2): 152-63.

Liang RP, Wang XN, Liu CM, Meng XY, Qiu JD, 2014. Facile preparation of protein stationary phase based on polydopamine/graphene oxide platform for chip-based open tubular capillary electrochromatography enantioseparation. Journal of Chromatography A. 1323: 135-42.

Mu C, Zhang L, Zhang X, Zhong L, Li Y, 2020. Selective adsorption of Ag (I) from aqueous solutions using Chitosan/polydopamine@C@magnetic fly ash adsorbent beads. Journal of Hazardous Materials. 381: 120943.

Noh JS, Schwarz JA, 1989. Estimation of the point of zero charge of simple oxides by mass titration. Journal of Colloid and Interface Science. 130(1): 157-64.

Özkan AE, Guven I, Gezici O, 2018. Protein ion-exchange chromatography on a biomacromolecule-immobilized monolithic cryogel. Turkish Journal of Chemistry. 42(2): 355-70.

Pan X, Zuo G, Su T, Cheng S, Gu Y, et al., 2019. Polycarboxylic magnetic polydopamine sub-microspheres for effective adsorption of malachite green. Colloids and Surfaces A: Physicochemical and Engineering Aspects. 560: 106-13.

Perçin I, Khalaf R, Brand B, Morbidelli M, Gezici O, 2015. Strong cation-exchange chromatography of proteins on a sulfoalkylated monolithic cryogel. Journal of Chromatography A. 1386: 13-21.

Pourfaraj R, Fatemi SJ, Kazemi SY, Biparva P, 2017. Synthesis of hexagonal mesoporous MgAl LDH nanoplatelets adsorbent for the effective adsorption of Brilliant Yellow. Journal of Colloid and Interface Science. 508: 65-74.

Reymond J., Kolenda F, 1999. Estimation of the point of zero charge of simple and mixed oxides by mass titration. Powder Technology. 103(1): 30-36. 
Scatchard G, 1949. The Attractions of Proteins for Small Molecules and Ions. Annals of the New York Academy of Sciences. 51(4): 660-72.

Schwarz J., Driscoll C., Bhanot A., 1984. The zero point of charge of silica-alumina oxide suspensions. Journal of Colloid and Interface Science. 97(1): 55-61.

Sun Z, Zhao L, Liu C, Zhen Y, Ma J, 2020. Fast adsorption of BPA with high capacity based on $\pi$ - $\pi$ electron donor-acceptor and hydrophobicity mechanism using an in-situ sp2 $\mathrm{C}$ dominant $\mathrm{N}$-doped carbon. Chemical Engineering Journal. 381: 122510.

Tang J, Song Y, Zhao F, Spinney S, da Silva Bernardes J, Tam KC, 2019. Compressible cellulose nanofibril (CNF) based aerogels produced via a bio-inspired strategy for heavy metal ion and dye removal. Carbohydrate Polymers. 208: 404-12.

Tempkin MJ, Pyzhev V, 1940. Recent modification to Langmuir isotherms. Acta Physiochem. USSR. 12: 21725.

Waite JH, 2008. Mussel power. Nature Materials. 7(1): 8-9.

Wang H, Wang Z, Yue R, Gao F, Ren R, et al., 2020. Rapid preparation of adsorbent based on mussel inspired chemistry and simultaneous removal of heavy metal ions in water. Chemical Engineering Journal. 383: 123107.

Wang Y, Ma X, Ding C, Jia L, 2015. pH-responsive deoxyribonucleic acid capture/release by polydopamine functionalized magnetic nanoparticles. Analytica chimica acta. 862: 33-40.

Wang Y, Wang S, Niu H, Ma Y, Zeng T, et al., 2013. Preparation of polydopamine coated Fe3O4 nanoparticles and their application for enrichment of polycyclic aromatic hydrocarbons from environmental water samples. Journal of Chromatography A. 1283: 20-26.

Wu M, Yuan J, Wu H, Su Y, Yang H, et al., 2019. Ultrathin nanofiltration membrane with polydopamine-covalent organic framework interlayer for enhanced permeability and structural stability. Journal of Membrane Science. 576: 131-41.

Xiao X, Wang W, Chen J, Jia L, 2015. Polydopamine-coated open tubular column for the separation of proteins by capillary electrochromatography. Journal of Separation Science. 38(16): 2893-99.

Yin Y, Yan L, Zhang Z, Wang J, 2015. Magnetic molecularly imprinted polydopamine nanolayer on multiwalled carbon nanotubes surface for protein capture. Talanta. 144: 671-79.

Yu Y, Shapter JG, Popelka-Filcoff R, Bennett JW, Ellis A V., 2014. Copper removal using bio-inspired polydopamine coated natural zeolites. Journal of Hazardous Materials. 273: 174-82.

Zeng R, Luo Z, Zhou D, Cao F, Wang Y, 2010. A novel PEG coating immobilized onto capillary through polydopamine coating for separation of proteins in CE. Electrophoresis. 31(19): 3334-41.

Zhan W, Gao L, Fu X, Siyal SH, Sui G, Yang X, 2019. Green synthesis of amino-functionalized carbon nanotubegraphene hybrid aerogels for high performance heavy metal ions removal. Applied Surface Science. 467468: 1122-33.

Zhang H, Yang F-Q, 2019. Applications of polydopamine modifications in capillary electrophoretic analysis. Journal of Separation Science. 42(1): 342-59. 